\title{
Analysis of Void Closure during Open Die Forging Process of Large Size Steel Ingots
}

\author{
Nathan Harris ${ }^{1, a^{*}}$, Davood Shahriari ${ }^{1, b}$ and Mohammad Jahazi ${ }^{1, c}$ \\ ${ }^{1}$ École de Technologie Supérieure, Département de Génie Mécanique, 1100, rue Notre-Dame \\ Ouest Montréal, Québec, H3C 1K3, Canada \\ anathan.harris.1@ens.etsmtl.ca, bdavood.shahriari@etsmtl.ca, cmohammad.jahazi@etsmtl.ca
}

\author{
Keywords: Void Closure, Hot Forging, Large Steel Ingot, FEM
}

\begin{abstract}
Large size forged ingots, made of high strength steel, are widely used in aerospace, transport and energy applications. The presence of internal voids in the as-cast ingot may significantly affect the mechanical properties of final products. Thus, such internal defects must be eliminated during first steps of the open die forging process. In this paper, the effect of in-billet void positioning on void closure throughout the ingot breakdown process and specifically the upsetting step in a large ingot size steel is quantitatively investigated. The developed Hansel-Spittel material model for new high strength steel is used in this study. The ingot forging process (3D simulation) was simulated with Forge NxT $1.0^{\circledR}$ according to existing industrial data. A degree of closure of ten virtual existing voids was evaluated using a semi-analytical void closure model. It is found that the upsetting process is most effective for void closure in core regions and central upper billet including certain areas within the dead metal zone (DMZ). The volumetric strain rate is determined and two types of inertial effects are observed. The dependence of void closure on accumulated equivalent deformation is calculated and discussed in relation to void in-billet locations. The original combination of information from both relative void closure and the volumetric strain rate provides a way to optimize the forging process in terms of void elimination.
\end{abstract}

\section{Introduction}

Internal voids can have harmful consequences on material integrity if left unchecked. Their elimination has therefore become a necessary part of the ingot forging process. One such prevailing technique is open die forging, shown to have a significant effect upon material transformation during ingot breakdown [1]. Voids, developed during the solidification of a large cast steel ingot [2] and mostly found in the central upper ingot and in core regions along the central axis [3], are significantly affected. Their closure ensuresa sound material, an effective forming process and industrial progress in this field. To this end, void closure predictions for large forgings have become a necessity.

The quantification of void closure predictions has been investigated by different researchers. Zhang et. al. [4] propose a semi-analytical formulation of the volumetric strain rate and relative void closure for the introduction of void closure models. Both indicators are dependent of physically interpretable notions such as material influence, $n$, triaxiality state, $T_{x}$ and accumulated deformation in-billet, $E_{e}$. It is the strain and the Norton exponent effect which reflects material sensitivity. The triaxiality of the stress state is known to greatly influence the amount of the plastic stain which a material may undergo before ductile failure occurs. It is defined as the ratio of hydrostatic pressure, or mean stress, to von Mises equivalent stress. Stress triaxiality factor is mathematically given as: 


$$
\frac{\sigma_{H}}{\sigma_{V M}}=T_{x}=\frac{\frac{1}{3}\left(\sigma_{1}+\sigma_{2}+\sigma_{3}\right)}{\sqrt{\frac{1}{2}\left\{\left(\sigma_{1}-\sigma_{2}\right)^{2}+\left(\sigma_{2}-\sigma_{3}\right)^{2}+\left(\sigma_{1}-\sigma_{3}\right)^{2}\right\}}}
$$

Although these parameters give a significant amount of information for successful void closure [5], their applicability to industrial size forgings demands the use of powerful simulation tools [6].

Numerical modelling of the forging process using the Finite Element (FE) method in a 2D [7] or $3 \mathrm{D}[8,9]$ environment has been a cornerstone for the optimisation of ingot forging in recent decades. Mostly based at a theoretical level, the relevance to industry was limited. As commercial codes and advanced theory $[10,11,12]$ developed, larger forgings were successfully simulated [13, 14] and more complex geometries/problems accounted for [15]. This meant that the simulation of internal defects, such as porosities and macro-segregation, began to give significant results in terms of understanding ingot forgeability [16]. Quicker and more precise computations consequently put 3D simulations at the cutting edge of process optimisation. However, industrial size ingot simulations remain computationally costly, their fully-combined potential with leading void closure models unexploited.

The current investigation aims to quantify the influence of volumetric strain rate on void closure and the importance of this parameter for a complete void closure analysis. A FE simulation of an industrial size high strength steel forging is developed to study the influence of void position on closure conditions. A dual sided justification for void closure is presented for several positions inbillet. The effects of the combined criteria are discussed for a plausible optimisation of the forging process.

\section{Finite Element Analysis}

Due to the size and weight of the considered ingot, 40 metric tonnes, finite element formulations were selected for resolution. The upsetting process was chosen because of the large deformation effects and consequent impacts upon the development of significant void closure factors such as triaxiality and macroscopic equivalent deformation. The latter is a technique aimed at increasing the width of a heated workpiece whilst reducing its length. The very large deformations during upsetting suffered by the material, result in large finite element distortions that require remeshing. The arbitrary Lagrangian Eulerian formulation proposes a very good understanding between these approaches. It has been implemented into the implicit code Forge NxT $1.0^{\circledR}[10]$. Throughout the actual upsetting process simulation via this software, thermo-mechanical fields are computed in a Lagrangian manner by implicitly solving the weak form of the balance and heat equations. The mesh velocity, $w$, is calculated in order to keep the best quality of elements to prevent mesh distortions. Remeshing allows transferring the state variables on the update mesh by considering $\left(\frac{d_{g} \varphi}{d t}-\varphi\right)$ terms that appear in the total derivative $\frac{d_{g} \varphi}{d t}$ of any variable $\varphi$ :

$$
\frac{d_{g} \varphi}{d t}=\dot{\varphi}+(w-v) \nabla \varphi
$$

Where $\dot{\varphi}$ is the material derivative of $\varphi$ representing the material's internal velocity, $v$.

\subsection{Finite element model}

A full field finite element simulation was generated in order to obtain significant data for macroscopic equivalent strain and stress tensor components using Forge NxT 1.0 ${ }^{\circledR}$. Initial ingot geometry was modelled using CATIA $V 5^{\circledR}$ and pre-upsetting geometry obtained as a result of previous forming techniques in a chain simulation. A schematic diagram is shown in Fig. 1. About 375000 tetrahedrons elements (80000 nodes) were used to discretize the ingot. The dies were modelled as rigid bodies and elastic-viscoplastic behaviour was assumed for the ingot material.An 
adaptive remeshing on deformation algorithm was implemented in order to increase resulting data precision. Two directions, press direction (vertical axis) and transverse direction (horizontal axis) were identified, as shown in Fig. 2. Thermal exchanges including conduction (die and ingot) and convection (circulating air and ingot) were considered in this model. The dies were preheated to $450^{\circ} \mathrm{C}$ and the ingots initial core temperature set at $1260^{\circ} \mathrm{C}$. Heat loss due to radiation was neglected. Contact between the ingot and the press dies was modelled using Coulomb's friction law.

A hydraulic press process was simulated using height reduction and press velocity parameters that were calculated thanks to data supplied by industrial partner, Finkl-Sorel Forge. An intermediate rigid die, was inserted between the upper die and the ingots top. Industrial data was analysed and a one hit pass equivalent for upsetting was identified for simulation.
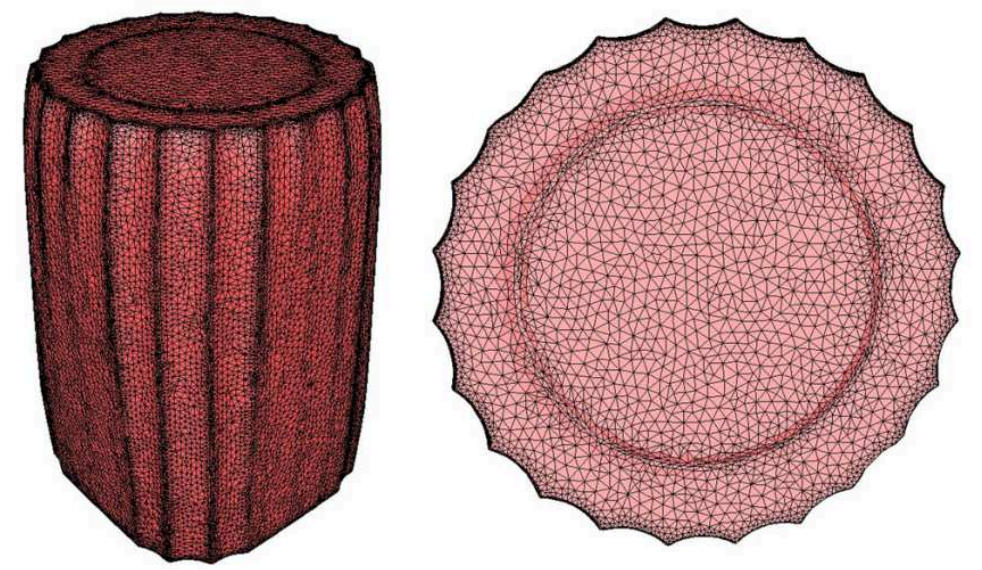

Fig. 1 : Ingot geometry and meshing.

\subsection{Rheological material model}

Newly developed high strength steel SF2000, as shown in Table 1, was selected for the present investigation. Hot compression tests were carried out on a Gleeble $3800^{\mathrm{TM}}$ with uniform temperatures ranging from $1050{ }^{\circ} \mathrm{C}$ to $1200{ }^{\circ} \mathrm{C}$ for strain rates from $0.25 \mathrm{~s}^{-1}$ to $2 \mathrm{~s}^{-1}$. The temperatures were chosen based on industrialingot forging operating conditions.

\begin{tabular}{ccccccc}
\multicolumn{6}{c}{ Table 1 : Chemical composition of SF2000 (\%wt) } \\
\hline $\mathrm{C}$ & $\mathrm{Mn}$ & $\mathrm{Si}$ & $\mathrm{Ni}$ & $\mathrm{Cr}$ & $\mathrm{Mo}$ & $\mathrm{Cu}$ \\
\hline 0.37 & 0.84 & 0.39 & 0.25 & 1.87 & 0.46 & 0.16
\end{tabular}

The Hansel-Spittellaw, Eq.3, was adopted using recently characterised material parameters to indicate the dependency of the flow stress on strain, strain rate and temperature[17].

$$
\sigma=2136.313 e^{-0.00243 T} \varepsilon^{0.2315} \dot{\varepsilon}^{0.1215} e^{\frac{0.0001}{\varepsilon}}(1+\varepsilon)^{-0.01 T} e^{0.3235 \varepsilon}
$$

This constitutive model is then implemented in the process in order to provide accurate prediction parameters.

\subsection{Void closure model}

Zhang's semi analytical void closure model [4] was selected as a base model to calculate void closure for large size ingots. The volumetric strain rate function, Eq.4, is obtained in order to account for void shape evolution which is essentially a factor to the specific material's macroscopic strain and internal stress state histories. Relative void volume, Eq.5, is achieved through hydrostatic integration, applying constant triaxiality values. The integrated form is therefore a discretised equation.

$$
\frac{\dot{V}}{\dot{E}_{e} V}=\operatorname{sign}\left(\Sigma_{m}\right)\left[\frac{3}{2}\left(\frac{3}{2 n}\left|T_{x}\right|+\frac{(n-1)(5 n+2)}{5 n^{2}}\right)^{n}+q_{1}\left|T_{x}\right|+3 q_{2} E_{e}^{2}+5 q_{3} E_{e}^{4}+q_{4}\right]
$$




$$
\frac{V}{V_{0}}=\exp \left\{-E_{e}\left[\frac{3}{2}\left(\frac{3}{2 n}\left|T_{x}\right|+\frac{(n-1)(5 n+2)}{5 n^{2}}\right)^{n}+q_{1}\left|T_{x}\right|+q_{2} E_{e}^{2}+q_{3} E_{e}^{4}+q_{4}\right]\right\}
$$

\subsection{Definition of virtual existing voids}

In order to obtain sufficient information on void closure for a significant segment of the ingot,ten virtual existing voids (A to J) were designated. Their positioning in regards to a section from the ingot centre/diameter is shown in Fig.2. The workpiece and loading symmetry involved during the upsetting process legitimizes the present investigationfor all of the ingot volume situated above the virtual line (A, E, F, G). Therefore, the effect of void position on void closure in a large size ingot can be examined in this area. The effect was studied along a vertical, horizontal and $45^{\circ}$ inclined axis in one of the billets diametric planes. The positioning was optimized to suit both the press $(\mathrm{Z})$ and transverse $(\mathrm{Y})$ forging directions.

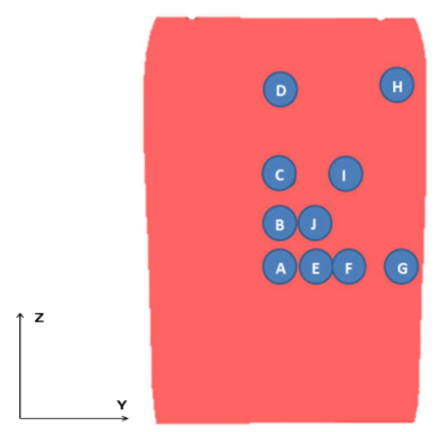

Fig. 2 : Void positioning scheme.

The positioning also allows the regrouping of several virtual existing voids to make up characteristic zones in the ingot. The designated zones, shown in Table 2, are useful for a global void closure analysis in a following paragraph.

Table 2 : Characteristic Ingot Regions

\begin{tabular}{c|cc}
\hline \multicolumn{2}{c}{$\begin{array}{c}\text { Positions } \\
\text { regrouped }\end{array}$} & \multicolumn{2}{c}{ Characteristic ingot region } \\
\hline A,E & Ingot core & Inner core \\
B,C,J,F & Ingot core & Outer core \\
I & Mid ingot ring & \\
G, & Outer ingot & Central outer ingot \\
H & Outer ingot & Upper outer ingot \\
D & Inner upper ingot (part of the DMZ) \\
\hline
\end{tabular}

\section{Results and Discussion}

\subsection{Void closure calculation method}

Data on triaxiality and macroscopic equivalent strain was gathered using a point tracking technique for the different positions described above. Fig. 2 Triaxiality was also calculated, using Eq.1, from stress tensor components considering a three dimensional state of stress[18].Both calculated and triaxiality taken from Forge $\mathrm{NxT} 1.0^{\circledR}$ software were found to differ less than $1 \%$. Fig. 3 and 4 show triaxiality and strain maps in a diametric plane towards the beginning of the upsetting process $(\mathrm{t}=10 \mathrm{~s})$.

The FE data was used in volumetric strain rate calculations with Matlab ${ }^{\circledR} 2013$, as shown in Fig. 5, evaluated using Zhang's semi analytical void closure model [4], Eq. 5. The current model was selected after its predictions were found to correlate with many findings concerning void closure during hot forging processes [2]. In order to account for specific high strength steel SF2000 material properties, adapted material constants $\left\{q_{1}, q_{2}, q_{3}, q_{4}\right\}$, used in Eq. 4 and 5, were calculated using rational polynomials, function to the materials Norton exponent, identified and approved using curve 
identification algorithms. The volumetric strain rate function, Eq. 4, was integrated for constant triaxiality states for $T_{x} \in[-1,0]$ in order to obtain relative void volume, Eq. 5, as shown in Fig. 6, for this triaxiality range.

\subsection{FE results}

Triaxiality is initially strongest, $T_{x} \rightarrow-1$, closest to the forging dies. The characteristic "blacksmith's cross" is visible for this parameter, the weakest compressive state, $T_{x} \rightarrow-0.2$, observed in the outer ingot mid-sectionclose to the surface. Intermediate triaxiality states, $T_{x} \in[-0.3,-0.5]$, are detected in the inner upper ingot.

Initial macroscopic equivalent strain is observed strongest, $E_{e} \rightarrow 0.56$, in the heart of the Dead Metal Zone (DMZ). The applied force from the upper die concentrates in this area also characterised by viscous material unable to move. Internal pressure therefore rises leading to increased strain. A second core for severe strain appears to develop just below the ingot centre.
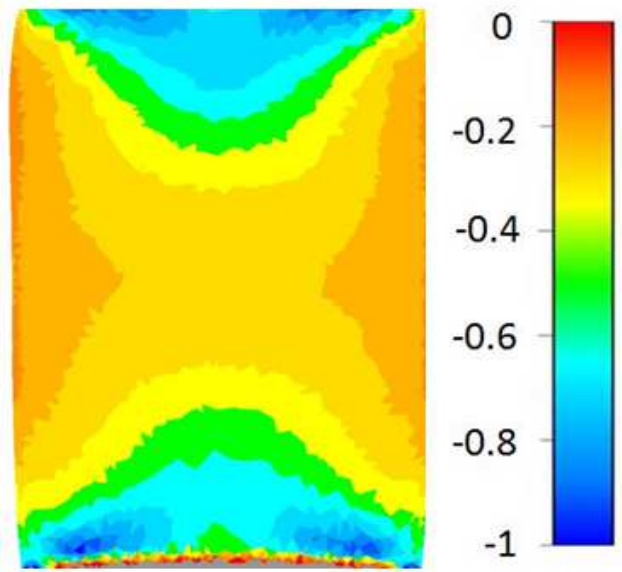

Fig.3 : Initial triaxiality evaluation during upsetting $(\mathrm{t}=10 \mathrm{~s})$.
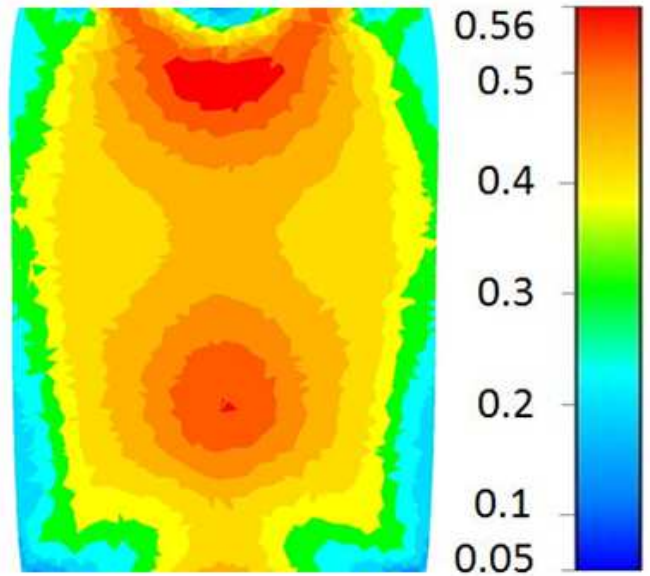

Fig. 4 : Initial macroscopic equivalent strain during upsetting $(\mathrm{t}=10 \mathrm{~s})$.

\subsection{Void closure analysis}

Two types of inertial effects were observed in accordance with in billet positioning. The first, a monotonous decreasing rate of closure was recognized for core locations, sensors A, B, J, E and F, and along the ingots principal axis, sensors $\mathrm{A}, \mathrm{B}, \mathrm{C}$ and $\mathrm{D}$. This type of closure corresponds to elevated terminal accumulated deformation and triaxiality state. The second, in a bell curve form, illustrates a strain rate dependence that increases during the initial phases of the upsetting process before decreasing at its end. It has been noted that the corresponding positions, I, $\mathrm{G}$ and $\mathrm{H}$, are all located far from the core in the ingots outer regions, mostly close to the surface. Relative void volume is shown in Fig. 6. Initially all voids are considered completely open, $\frac{V}{V_{0}}=1$. These values were not represented for considerations concerning graph clarity only. As a general rule, the upsetting process is observed to become less effective, regarding void closure, the further the void location is found from the billets centre (position A). Void closure effectiveness can be found inTable 3. This rule is confirmed along all three studied axis with the exception of position $\mathrm{D}$, found in the Dead Metal Zone (DMZ), for which, void closure appears almost immediate. A closer look at relative void volume, Fig. 6, reveals that void closure in function to void position is a gradual phenomenon that can be quantified by zone. Similar rates of void closure were observed for: positions $\mathrm{A}$ and $\mathrm{E}$ (the inner core) andpositions $\mathrm{B}, \mathrm{C}, \mathrm{J}$ and $\mathrm{F}$ (the outer core). Other zones, characterised in Table 2, all showed unique results for void closure. The outer region, central outer region (position $\mathrm{G}$ ) and the upper outer region (position $\mathrm{H}$ ), showed the least favourable conditions for void closure. Out of these two, position $\mathrm{H}$, displayed the least effective void closure for the upsetting phase. 
Combining the information from both Fig. 5 and 6 can better illustrate the results. Fig. 6 shows the void position $\mathrm{D}$ to be the most effective for void closure. However, position D isalso shown to appear in the billets DMZ figuring no material displacement. Fig. 5 reveals a near non-existent dependence (less than 5\%) on strain at this particular location during the entire upsetting phase. Position $\mathrm{H}$ shows the least gain in void closure, Fig. 6. This in-DMZ location exhibits low triaxiality states, $\left|T_{x}\right|<0.4$, but not as little as in the central outer region, $\left|T_{x}\right|<0.3$. However, the relative void volume in position $G$ decreases quicker than in position H. Fig. 6 helps clarify the phenomenon. Position $\mathrm{H}$ has longer time related dependence on strain variation (larger bell curve), even though maximum volumetric strain rate is similar. Void closure for $\mathrm{H}$ is therefore more difficult because of it being more strain dependent for a longer period of time than in $\mathrm{G}$.

Table 3: Void closure effectiveness per axis

\begin{tabular}{c|cccc}
\hline \multirow{2}{*}{ Axis } & \multicolumn{4}{|c}{ Void Closure Effectiveness } \\
\\
Mertical & D & A & B & Least Effective \\
Horizontal & A & E & F & G \\
$45^{\circ}$ Inclined & A & J & I & H \\
\hline
\end{tabular}

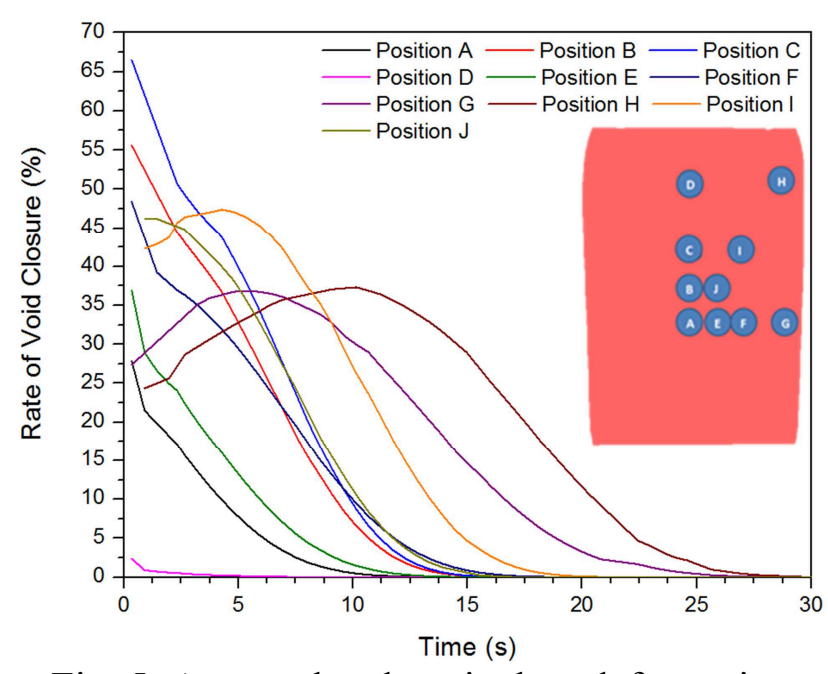

Fig. 5: Accumulated equivalent deformation dependence during ingot upsetting.

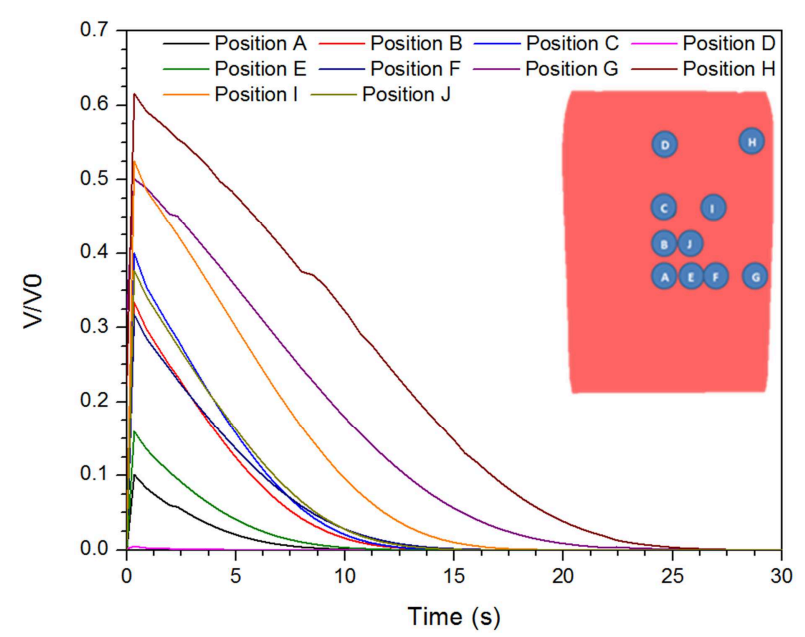

Fig. 6: Relative void closure during the upsetting process.

\section{Conclusion}

A methodology is proposed to evaluate void closure and observe corresponding forging effects in an industrial size high strength steel ingot. Initial void positon (particularly central regions) and relative strain dependence have significant effects on the void closure.Void closure, although linearly gradual (axis $\mathrm{Y}$ and $\mathrm{Z}$ ), can be observed by zone. The outer ingot, especially upper outer ingot, must be targeted in order to optimize the forging process.

\section{Acknowledgements}

The authors wish to express their gratitude to Finkl Steel-Sorel Co. for providing the equipment for the present research. The authors would like to appreciate NSERC for their support in the framework of a Collaborative Research and Development project (CRD), and Transvalor Americas Corp for permission to use Forge NxT $1.0^{\circledR}$ software. The authors acknowledge access to high performance supercomputers at CLUMEQ. 


\section{References}

[1] S.P. Dudra, Y.-T. Im, Analysis of void closure in open-die forging. Int. J. Mach. Tool. Manu. 30(1) (1990) 65-75.

[2] B.J. Lee, M.E. Mear, Studies of the growth and collapse of voids in viscous solids. J. Eng. Mater-T. 116(3) (1994) 348-358.

[3] M. Tkadlečková, K. Michalek, K. Gryc, B. Smetana, P. Machovčák, L. Socha, The effect of boundary conditions of casting on the size of porosity of heavy steel ingot. Journal of Achievements in Materials and Manufacturing Engineering 56(1) (2013) 29-37.

[4] X.-X. Zhang, Z.-S. Cui, W. Chen, Y. Li, A criterion for void closure in large ingots during hot forging. J. Mat. Process. Tech. 209(4) (2009) 1950-1959.

[5] M. Saby, P.O. Bouchard, M. Bernacki, Void closure criteria for hot metal forming: A review. Journal of Manufacturing Processes 19(0) (2015) 239-250.

[6] Y.C. Lin, M.-S. Chen, J. Zhong, Numerical simulation for stress/strain distribution and microstructural evolution in 42CrMo steel during hot upsetting process. Comp. Mater. Sci. 43(4) (2008) 1117-1122.

[7] H. Kakimoto, T. Arikawa, Y. Takahashi, T. Tanaka, Y. Imaida, Development of forging process design to close internal voids. J. Mater. Process. Tech. 210(3) (2010) 415-422.

[8] Y.S. Lee, S.U. Lee, C.J. Van Tyne, B.D. Joo, Y.H. Moon, Internal void closure during the forging of large cast ingots using a simulation approach. J. Mater. Process. Tech. 211(6) (2011) 1136-1145.

[9] M. Saby, M. Bernacki, E. Roux, P.O. Bouchard, Three-dimensional analysis of real void closure at the meso-scale during hot metal forming processes. Comp. Mat. Sci. 77(0) (2013) 194-201.

[10] FORGE NxT 1.0 ®, Transvalor S.A. : 694 av. Donat, 06255 Mougins Cedex, France.

[11] X.-X. Zhang, Z.-S. Cui, Theoretical study of void closure in nonlinear plastic materials. Appl. Math. Mech. 30(5) (2009) 631-642.

[12] Z.P. Huang., J. Wang., Nonlinear mechanics of solids containing isolated voids. Appl. Mech. Rev. 59 (2006) 210-229.

[13] K. Chen, Y. Yang, G. Shao, K. Liu, Strain function analysis method for void closure in the forging process of the large-sized steel ingot. Comp. Mat. Sci. 51(1) (2012) 72-77.

[14] B. Xu, M. Sun, D. Li, Modeling of the void close behavior in a 100t ingot during hot forging. Steel Res. Int. 43(0) (2012) 215-218.

[15] X. Zhang, F. Ma, K. Ma, X. Li, Multi-scale analysis of void closure for heavy ingot hot forging. Modern Appl. Sci. 6(10) (2012) 15-25.

[16] M. Saby, M. Bernacki, and P.-O. Bouchard, Understanding and modeling of void closure mechanisms in hot metal forming processes: A Multiscale Approach. Procedia Engineering 81(0) (2014) 137-142.

[17] K.Chadha, D.Shahriari, M.Jahazi, An approach to develop Hansel-Spittel constitutive equation during ingot breakdown operation of low alloy steels. FiMPART, 2015

[18] S. Kut, State of stress identification in numerical modeling of 3D issues. Arch. Metall. Mater. 54(3) (2009) 672-632. 